\title{
Severe orthostatic hypotension associated with carcinoma of the bronchus
}

\author{
G. J. GREEN* \\ B.Sc., M.B., M.R.C.P. (U.K.) \\ A. M. BRECKENRIDGE* \\ M.D., M.Sc., F.R.C.P. \\ F. K. WRIGHT $\dagger$ \\ M.B., M.R.C.P. \\ ${ }^{*}$ Royal Southern Hospital, Liverpool, and Department of Pharmacology and Therapeutics, University of \\ Liverpool; †Royal Alexandra Hospital, Rhyl, Clywd
}

\begin{abstract}
Summary
A patient is described who had severe orthostatic hypotension. An account is given of his treatment with a monoamine oxidase inhibitor and tyramine. At post-mortem, 8 months after the illness began, a small oat cell carcinoma of the bronchus was found. It is suggested that the orthostatic hypotension was a nonmetastatic manifestation of the underlying carcinoma.

\section{Introduction}

Idiopathic postural hypotension was first described by Bradbury and Eggleston in 1925 and they suggested that it was caused by paralysis of the sympathetic vasoconstrictor nerve endings. A variety of systemic diseases affecting the central and peripheral nervous system have subsequently been documented as causes of orthostatic hypotension and it is now known that the final factor in causing orthostatic hypotension is a failure of noradrenaline release from vasoconstrictor nerve endings (Bannister, Sever and Gross, 1977).

In the following case report, no definite cause for the orthostatic hypotension was found during life but post-mortem revealed a possible answer.
\end{abstract}

\section{Case history}

A 73-year-old male retired army officer had a sudden onset of persistent dizziness on standing upright in October 1976 and this progressed to losses of consciousness on standing up, over a period of a few days. These symptoms continued and he was admitted to hospital in January 1977 by which time he was confined to either lying in bed or sitting in a chair. His only other symptoms were fatigue, anorexia and some numbness and paraesthesiae in his hands and feet. He denied problems with micturition, impotence or lack of sweating and he had no cough or sputum. He was receiving no drug therapy, did not drink alcohol excessively but had smoked 15-20 cigarettes/day for many years. His only previous illness was a vagotomy and gastrojejunostomy for a duodenal ulcer in November 1965. His father had died of a carcinoma of the lung.

Examination revealed a thin man weighing $66 \mathrm{~kg}$ with no lymphadenopathy or finger clubbing. The cardiovascular system was normal apart from his blood pressure (diastolic measured at phase IV) which was $140 / 80 \mathrm{mmHg}$ supine, $100 / 50$ $\mathrm{mmHg}$ standing and $60 / 0 \mathrm{mmHg}$ after mild exercise. His pulse was regular at $72 / \mathrm{min}$ and the rate did nog change significantly when his blood pressure fell o on performing a Valsalva manoeuvre. The respir atory system, abdominal and rectal examinations? were normal but he was found to have a mild sensory and motor peripheral neuropathy. There was absent vibration sense in his legs from the ankles to the anterior superior iliac spines with absent knee and ankle jerks. Both plantar responses were flexor and joint position sense and other sensory parameters normal. In the upper limbs biceps jerks were absent but there was no obvious sensory loss. Romberg's test was negative, there was no ataxia or extrapyramidal signs. His cranial nerves and higher cerebral functions were normal.

Investigations. Haemoglobin $14.2 \mathrm{~g} / \mathrm{dl} ; \mathrm{MCV}$ $89 \mathrm{fl}$; serum $B_{12} 70 \mu \mathrm{g} / \mathrm{l}$ (normal range $120-428$ $\mu \mathrm{g} / \mathrm{l})$; bone marrow, normoblastic with increased erythroid activity; Dicopac ratio $2 \cdot 18$, indicating lack of intrinsic factor; pentagastrin-fast achlorhydria. The following tests were all normal: white cell count, platelet count, ESR, blood film, urea and electrolytes, $2 \mathrm{hr}$ postprandial blood sugar, serum folate, Synacthen test, proteins and electrophoresis, liver function tests, WR and Reiter protein complement fixation test negative, chest X-ray (subsequently repeated supine $15 \cdot 3 \cdot 77$ and $5 \cdot 4 \cdot 77$ ) skull X-ray, skeletal survey, ECG and barium enema. A barium meal confirmed the gastrojejunostomy and showed emptying of the stomach by this route and by the duodenum. 
He was treated with 5 daily injections of cyanocobalamin $1000 \mu \mathrm{g}$, folic acid $5 \mathrm{mg}$ thrice daily, and fludrocortisone $100 \mu \mathrm{g}$ twice daily with potassium supplements. The head of the bed was raised at night and he wore full length elastic stockings. Initially he improved and was able to walk about the ward and had blood pressures of $170 / 90 \mathrm{mmHg}$ supine and $120 / 70 \mathrm{mmHg}$ standing. However, he relapsed after a few weeks and increasing the fludrocortisone to 200 $\mu \mathrm{g}$ thrice daily did not help. His symptoms remained, with blood pressures of $150 / 70 \mathrm{mmHg}$ lying and 50/0 $\mathrm{mmHg}$ standing. In March 1977, he developed retention of urine with overflow incontinence and was catheterized. He was now completely bedbound and was complaining of weight loss, impotence and constipation with occasional episodes of diarrhoea and he was re-admitted to hospital for reassessment of treatment. Examination showed a lucid man with muscle wasting, weighing $58 \mathrm{~kg}$ with a peripheral neuropathy as previously documented. Blood pressure was $130 / 70 \mathrm{mmHg}$ lying and unrecordable on standing when he lost consciousness. Pulse rate was 70 beats/min and was unchanged by posture. Repeat investigations revealed no new abnormalities, his serum $B_{12}$ was now normal but an EEG was abnormal with a marked delta rhythm in the left midzone region.

At this stage it was decided to treat him with a combination of tyramine and tranylcypromine, a monoamine oxidase inhibitor. Initially an intravenous infusion of tyramine solution alone was given at different concentrations (Table 1) and this had no appreciable effect on the supine and none on the standing blood pressure. Tranylcypromine $10 \mathrm{mg}$ thrice daily was then started and 7 days later the intravenous tyramine infusion test was repeated with the lowest concentration previously used (Table 2 ). This caused an elevation in his supine and standing blood pressures and treatment was therefore continued with tranylcypromine and tyramine capsules $10 \mathrm{mg}$ thrice daily over the next few weeks. During this time he was able to walk short distances unaided and his blood pressure was $140 / 70 \mathrm{mmHg}$ lying and $80 / 50 \mathrm{mmHg}$ standing. However, the effectiveness of this therapy soon wore off (Table 3) and because of developing confusion and paranoid feelings the tranylcypromine was stopped. His standing blood pressure was once again unrecordable and in June 1977 he developed a right hemiparesis and soon afterwards died. At post-mortem, a small carcinoma in the apical segment of the left upper lobe bronchus was found, 3 $\mathrm{cm}$ below the apex of the lung. There was also a mass of neoplastic lymph nodes around the left hilum encasing the vagus nerve. The right vagus nerve was intact. Two secondary brain deposits were found: one $3 \mathrm{~cm}$ in diameter at the junction of the left frontal and parietal lobes, and the other involving the lower midbrain, pons and upper medulla extending from the left- to the right-hand side of the brainstem. Histology of the tumour showed it to be an oat cell carcinoma.

\section{Discussion}

That the patient had a clinically and radiologically silent bronchial carcinoma in the presence of severe orthostatic hypotension for 8 months seems unique. Although the association of bronchial carcinoma and orthostatic hypotension has been reported before, the clinical course of this patient was different from those previously documented (Ivy, 1961; Siemsen and Meister, 1963; Lhermitte et al., 1970; Park et

TABLE 1. Effect of tyramine infusions on blood pressure

\begin{tabular}{ccccc}
\hline $\begin{array}{c}\text { Tyramine infusion rate } \\
(\mu \mathrm{g} / \mathrm{min})\end{array}$ & $\begin{array}{c}\text { Time infusion given } \\
(\mathrm{min})\end{array}$ & $\begin{array}{c}\text { Supine blood pressure } \\
(\text { measured every 2 min) } \\
(\mathrm{mmHg})\end{array}$ & $\begin{array}{c}\text { Standing blood pressure } \\
\text { Nil }\end{array}$ & $\begin{array}{c}\text { Pulse rate } \\
(\mathrm{beats} / \mathrm{min})\end{array}$ \\
100 & 40 & $1150 / 75$ & unrecordable & 82 \\
300 & 15 & $132-150 / 68-74$ &, & 80 \\
1000 & 15 & $130-138 / 70-76$ &, & 80 \\
\hline
\end{tabular}

TABLE 2. Effect of tyramine infusion on blood pressure after tranylcypromine therapy for one week

\begin{tabular}{ccccc}
\hline $\begin{array}{c}\text { Tyramine infusion rate } \\
(\mu \mathrm{g} / \mathrm{min})\end{array}$ & $\begin{array}{c}\text { Time infusion given } \\
(\mathrm{min})\end{array}$ & $\begin{array}{c}\text { Supine blood pressure } \\
(\mathrm{mmHg})\end{array}$ & $\begin{array}{c}\text { Standing blood pressure } \\
(\mathrm{mmHg})\end{array}$ & $\begin{array}{c}\text { Pulse rate } \\
(\mathrm{beeats} / \mathrm{min})\end{array}$ \\
\hline $\mathrm{Nil}$ & & $182 / 88$ & $70 / 50$ & 66 \\
100 & 10 & $195-230 / 95-120$ & - & 62 \\
Nil over subsequent $50 \mathrm{~min}$ & & $205-235 / 95-118$ & $95-180 / 60-85$ & 72 \\
\hline
\end{tabular}


TABLE 3. A summary of the patient's progress

\begin{tabular}{cccl}
\hline \multicolumn{5}{c}{$\begin{array}{c}\text { Blood pressure } \\
(\mathrm{mm} \text { Hg) }\end{array}$} & \\
Date & Supine & Standing & Treatment \\
\hline Jan. 77 & $140 / 80$ & $100 / 50$ & Nil \\
& $170 / 90$ & $120 / 70$ & B $_{12}$, folic acid, fludrocortisone, elastic stockings, bedhead raised at night \\
Feb. 77 & $150 / 70$ & $50 / 0$ & Fludrocortisone \\
Mar. 77 & $130 / 70$ & $0 /-$ & Fludrocortisone \\
Apr. 77 & $140 / 70$ & $80 / 50$ & Tyramine capsules, tranylcypromine, fludrocortisone \\
Jun. 77 & $140 / 75$ & $0 /-$ & Fludrocortisone \\
\hline
\end{tabular}

al., 1972; Boasberg et al., 1977). Initially it was thought that he had true idiopathic orthostatic hypotension but the rapid onset and deterioration of symptoms is unlike the cases originally described by Bradbury and Eggleston (1925) and the absence of central nervous system signs is unlike the cases described by Shy and Drager in 1960 . The presence of weight loss, muscle wasting and a mixed peripheral neuropathy suggested a diagnosis of carcinomatous neuropathy (Henson, Russell and Wilkinson, 1954) but no evidence for this was found. The low serum $B_{12}$ was attributed to his previous gastrojejunostomy and may have contributed to his peripheral neuropathy but it is improbable that it caused postural hypotension which became steadily worse even though his $\mathbf{B}_{12}$ deficiency was corrected. Having excluded other causes of postural hypotension (adrenal insufficiency, diabetes, syphilis, Parkinsonism), the sympathetic nervous system was investigated further by means of an i.v. tyramine test (Demanet, 1976) before and after monoamine oxidase therapy, to see if a therapeutic response could be obtained (Nanda, Johnson and Keogh, 1976).

Tyramine is an indirect sympathomimetic amine and is effective only in patients with relatively intact sympathetic nerve endings. Monoamine oxidase inhibitor therapy was given in an attempt to potentiate the effect of any noradrenaline released by the tyramine. Tyramine hydrochloride powder was obtained by the pharmacy and made up into solution or into $10-\mathrm{mg}$ capsules. The first tyramine test using infusions $\leqslant 1000 \mu \mathrm{g} / \mathrm{min}$ achieved no significant increase in the supine or standing blood pressure. The second tyramine infusion following therapy for one week with tranylcypromine was more successful. The supine and standing blood pressures were higher than before tranylcypromine therapy and were further elevated by an infusion of tyramine $100 \mu \mathrm{g} / \mathrm{min}$ for $10 \mathrm{~min}$ and this elevation was maintained for one hour. This therapy was therefore continued orally in addition to the fludrocortisone and potassium therapy which is thought to be of benefit by causing volume expansion. However, the beneficial effect of this combined therapy was only sustained for a few weeks, a result similar to the effect of other forms of therapy in the treatment of orthostatic hypotension (Bannister, Ardill and Fenton, 1969).

The finding of a bronchial oat cell carcinoma at post-mortem suggested that this has been the cause of the patient's severe orthostatic hypotension an considering the clinical course of the hypotension it likely that this was a non-metastatic rather than metastatic complication.

\section{Conclusion}

The patient had an autonomic and peripheral neuropathy with severe orthostatic hypotension which responded poorly to various therapeutic manoeuvres. Initial improvement of the postural hypotension with tyramine and tranylcypromine was not sustained. It is suggested that this patient's severe postural hypotension which was present for 8 months before his death, was a non-metastatic complication of an underlying bronchial oat cell carcinoma, which interfered with reflex vasoconstriction on standing.

\section{Acknowledgment}

We wish to thank Dr J. T. Alban Lloyd for performing the post-mortem examination.

\section{References}

Bannister, R., Sever, P. \& Gross, M. (1977) Cardiovascular reflexes and biochemical responses in progressive autonomic failure. Brain, 100, 327.

Bannister, R., Ardill, L. \& Fenton, P. (1969) An assessment of various methods of treatment of idiopathic orthostatic hypotension. Quarterly Journal of Medicine, 38, 377.

Boasberg, P.D., Henry, J.P., Rosenbloom, A.A., Hall, T.C., Rose, M. \& Fisher, D.A. (1977) Case reports and studies of paraneoplastic hypotension. Medicine and Paediatric Oncology, 3, 59. 
Bradbury, S. \& Eggleston, C. (1925) Postural hypotension - a report of three cases. American Heart Journal, 1, 73.

DEMANET, J.C. (1976) Usefulness of noradrenaline and tyramine infusion tests in the diagnosis of orthostatic hypotension. Cardiology, 61 (Suppl. 1), 213.

Henson, R.A., Russell, D.S. \& Wilkinson, M. (1954) Carcinomatous neuropathy and myopathy. A clinical and pathological study. Brain, 77, 82.

IvY, H.K. (1961) Renal sodium loss and bronchogenic carcinoma. Archives of Internal Medicine, 108, 47.

Lhermitte, F., Gautier, J.C., Escourolle, R., Derouesné, C. \& VÉron, J.P. (1970) Hypotension orthostatique et neuropathie périphérique au cours de l'évolution d'un carcinome bronchique. Presse Médicale, 78, 257.
NANDA, R.N., Johnson, R.H. \& KeOGH, H.J. (1976) Treatment of neurogenic orthostatic hypotension with a monoamine oxidase inhibitor and tyramine. Lancet, ii, 1164.

Park, M.P., Johnson, R.H., Crean, G.P. \& Robinson, J.F, (1972) Orthostatic hypotension in bronchial carcinoma. British Medical Journal, 3, 510.

Shy, G.M. \& Drager, G.A. (1960) A neurological syndrome associated with orthostatic hypotension. A clinicalpathologic study. Archives of Neurology, 2, 511.

SiEmSEN, J.K. \& MeIsTer, L. (1963) Bronchogenic carcinoma associated with severe orthostatic hypotension. Annals of Internal Medicine, 58, 669. 